

\title{
Chosen Problems of Contemporary Management in Modern Economy
}

\author{
Beata Glinkowska, Boguslaw Kaczmarek \\ University of Lodz, Lodz, Poland
}

\begin{abstract}
The modern economy raises new challenges for companies as entities in business and managers, as organizers and managers of functioning and operation of these companies. What needed is a change in the orientation of the theory and practice of management thinking, to whom and why organized, collective action and encouragement of entrepreneurship must serve, and what should be the mission of a modern and effective management science. An important issue appearing is to build a profile of the modern manager, who faces serious, new, and often unfamiliar challenges. The modern manager must be primarily flexible, resistant to stress, and willing to take risks and enthusiastic. The subject of the article is some problems of modern management of organization. The aim of this article is to describe and analyze the changes in the environment and for modern governance. The study attempted to answer the question: what the challenges faced by today's managers in the management of enterprises. This article is based on the analysis of literature, and diversified in cross time.
\end{abstract}

Keywords: contemporary management, new management, modern management, contemporary economy, new economy, modern economy

\section{Introduction to the Issues}

Modern organizations are operating in an unfavorable environment, understood as the totality of phenomena, processes, and institutions that shape their interchangeable relationship, sales opportunities, scope, and growth prospects. More challenging and uncertain setting reduces the ability to earn the company a sustainable existence and long-term development. It becomes necessary to define proper market needs and satisfy them more effectively than does the competition (Hutt \& Speh, 1997, p. 29). These difficulties are leading a modern enterprise result among others, from the followings:

- increasing complexity of the environment, the market, and the risk, due to the ongoing process of internationalization and globalization; the difficulty of accurate future forecasting and programming increases;

- a growing number of factors (variables) that determine the success of the company. Also growing the importance of flexible acting integrated with the needs of customers, the interests of various entities, which are the market participants;

- even best designed plans are rapidly becoming outdated. The number of possible solutions is increasingly bigger, unfortunately the costs of inaccurate assessment of prospective benefits are higher;

Beata Glinkowska, Ph.D., Faculty of Management, University of Lodz, Lodz, Poland.

Boguslaw Kaczmarek, prof., Faculty of Management, University of Lodz, Lodz, Poland.

Correspondence concerning this article should be addressed to Beata Glinkowska, Faculty of Management, University of Lodz, Lodz, Poland. 
- an increasing number of both domestic and international events affect the behaviour and business development programming. Various new forms of cooperation are being created;

- shorter period for which you can plan with the desired degree of certainty, and the key to success is to receive fresh signals from the market and implement them as soon as possible;

- increasing demands on the quality and timeliness of delivery and service;

- significantly less time to transfer, prepare, and store information, its value and usefulness to businesses is decreasing. At the same time, the cost of acquiring information is increasing;

- there is a significant acceleration of processes;

- growing public interest in the humanities and economic problems, social responsibility of enterprises is a priority;

- democratization process is progressing. Uncertainty and changeability of the social system are growing, which creates an imbalance (increase in labour mobility, need for competition, job insecurity, etc.) and the associated difficulties in adapting to the new conditions of work and life.

\section{New Challenges for Companies-Review of the Literature}

Changeability of environment forces companies to continuously improve their own processes, structure, and culture, build their own distinctive abilities, and explore new success factors. An important thing is to obtain necessary reputation.

Each company is facing the problem of strategy selection of its actions and factors guaranteeing success (Wawrzyniak, 1996, pp. 7-10). In this regard, the theory and practice of management provide a lot of valuable tips and examples that will definitely help to achieve success. The greatest factor in the success of modern business is knowledge. "The knowledge - they write - is, for today's business, the environment even more important than the banking, political, or energy system. (...) Knowledge becomes a universal substitute for all of the resources: "the key task of a developed economy" (A. Toffler \& H. Toffler, 1996). Due to knowledge, a company becomes a smart organization, and able to learn and adjust to the structure of the environment, the expected results, or lack thereof, to generate appropriate innovations and verify them on the market, as well as to build its own future (Grudzewski \& Hejduk, 1997). Kay (1996, p. 32) argued that success is the result of using the abilities which permanently distinguish the company. Sources of these capabilities are: innovation, architecture (the system of relations within a company or among the company and its suppliers and customers, or both), reputation, and its strategic resources. Marketing experts believe that well-run marketing is the most important source of business success, which aims to satisfy the existing customers with supremacy of value (Kay, 1996, p. 32). All its actions should be aimed at building and sustaining profitable relationships with stakeholders, which should be a major value for a modern company (Hutt \& Speh, 1997, p. 37).

American study conducted in 43 "best" companies, representing various sectors of the economy, showed that the most important factors of company's success were (McKenna, 1991):

- tendency to act, to undertake, which is a constant enforcing rapid analysis of emerging problems, formulating answers, and immediate implementing the proposed solutions to best serve the market. The speed of making decisions is a key to the success;

- close and direct contact with customers, which is based on the knowledge of their needs, preferences, and tastes, and fast and reliable meeting them; 
- autonomy and entrepreneurship which involves creating an environment of self-reliance of individuals and teams capable of initiatives and innovations;

- productivity and efficiency by the people, which means creating in all employees the belief that good work is essential, and that they will have the benefits of the company's success and growth of its reputation;

- focus on values, which is a particular emphasis on the value realized by the company and the resulting operating philosophy;

- clinging to its specialty, which means focusing on basic profile of the company;

- simple organizational structure and a small staff, which means keeping a small number of management levels in the structure.

It must be argued here that more modern companies are becoming knowledge-based organizations, the increasing role in shaping their success plays social factors. The most important of these are: social responsibility, focus on people, internal negotiations, and ethics of action (Bloom, Calori, \& Woot, 1995, p. 25).

Social responsibility means that companies see themselves as an integral part of society and therefore act in a socially responsible manner, ethically, fulfilling their civic duty, a kind of commitment to the community. Therefore, they do not believe that profit is the only goal of business; it is equally important to ensure the company the long-term existence and positive image in the environment (environmental protection, public relations). That is why they are not only trying to meet legal obligations, but also to invest in human capital, the environment, and relations with stakeholders, and thus voluntarily invest in the improvement of society and the environment (Falck, 2003; Bazzichi, 2003).

Focus on the people is the belief that workers should take advantage of the progress and the generated profit. Enterprises implement that by raising wages, tolerating differences in personality, increasing quality of life of their employees, and improving human resource management practices.

Internal negotiations, in turn, mean that in companies decisions are taken through negotiating on ideas and reaching an agreement or compromise by various parties. The functioning of a modern enterprise is a specific market game.

Changing company has now become an organization conscious of its social duties and at the same time acting ethically (Zbiegień-Maciagg, 1996, p. 32). Ethical business is an organization that in its mission already includes a certain level of management culture that will be guided by the principle-profit, but not at any price. Many companies develop their own codes, norms, and values, which in turn, over time, are rooted in the minds of the employees (Zbiegień-Maciagg, 1996, p. 34).

Success of the organization can not be provided without taking care of people, and without proper human resources policy, improvement of working conditions, motivation, and communication, as well as building a positive image of itself in the environment. Crozier (2003, pp. 30-35), for example, believed that "prosperity and success of the organization, so required in the new economic logic, will depend primarily on the development of human ability to learn and improve" and therefore

It should be tested every opportunity offered by the world in which human resources are the most important (...). Investing in the development of people, their awareness, education and experience should take more and more important place as compared to investing in the material realm, which may be of secondary importance for structuring processes. (Crozier, 2003) 
An important condition for the creation of modern organizations is to integrate employees with the company. Creative motivation of entrepreneurs is not enough, but it is also necessary to mobilize employees, allow focusing joint effort and assets on the things that bring the company better market effects, or increase its value in the market. Fast and flexible responses to market challenges require partnership, negotiation, cooperation, and ability to deal with people and issue commands in such way that they are fast and well done, with the involvement of the employee's own initiative. Wawrzyniak (2007, p. 17), examining determinants of entrepreneurship, stated that whether the company is entrepreneurial depends on the factors inherent in itself as well as those outside. The importance of policy for the management of human resources in generating and solving internal business seems to be clear and indispensable for the functioning of businesses and the creation of their success.

Companies must be more sensitive to the internal staff affairs and public affairs. They have to skilfully adjust interests of customers, employees, and the public to their own objectives. Above all, they need to invest in human capital, increase the intellectual potential because it is essentially conditioned by their entrepreneurial skills; creating an organization of the social needs of tomorrow, which clearly shows the efficiency of the economic integration of the humanistic management rules.

\section{New Requirements for Managers-Review of the Literature}

Modern managers of Polish companies, in the opinion of the researchers (for example: K. Doktór, B. Wawrzyniak, J. Gladys-Jakóbik, J. Lipecki, S. Lachiewicz, B. Kaczmarek, J. Penc, and B. Glinkowska) of this phenomenon, they should focus in their managerial work on personnel policy and profitable investment in human capital, which is a major factor in the development and enrichment of the organization. To effectively compete in the market, companies must attract, retain, and motivate above all effectively use the abilities of the most talented employees that they will be able to obtain. They must also carry out continuous training of crews, teaching them new skills and new behaviours in order to be able to understand the changes, accept them, and taking effective action. In view of the growing popularity of "losing weight" and reorganization, a system of social protection and stress managing must be actively involved in the process of training and re-qualification. They have to provide employees with the opportunity to improve their skills, in stress free conditions to enable them a chance to take on new work, or start their own innovative business, which will weaken the resistance to change (Penc, 2005).

However, it seems that the most important challenge for contemporary managers is to become aware and understand that “(...) job and existence insecurity affected almost everyone” (Penc, 2010, p. 16).

In a well-designed society, the sense of justice is the good of each person, everyone has the opportunity to actively participate in public, according to the position they occupied in the society and the applicable system of values. In such a community, the use of the property is consistent with the common welfare and people properly fulfil their duties and obligations, and not only enjoy the privileges given them by the power or possession of property.

Penc (2010, p. 18) claimed that:

The principal task of the state is to ensure the safety so that the man who works and produces could enjoy the fruits of this work, and thus, there was an incentive to do it efficiently and fairly. (...) The duty of the state is to promote business activity by creating conditions which ensure the opportunity to work, to provide incentives where this activity is insufficient, or providing assistance in times of crisis. The state has the right to invest when specific situations caused by the existence of a monopoly cause recession or the obstacles for development. 
Managers must, therefore, acquire and strengthen the skills of alignment in the production and profitability with social and environmental renewal, and thus make the turn to ethics-including ethics of entrepreneurship, which enables better use of the knowledge and skills of people in the service of business, society, and the environment (Penc, 2010).

Economics and ethics are not mutually exclusive.

Institutions educating managers should create and develop a new manager model, focuse more on the people and the capital of knowledge and take into account wider international and multicultural aspects. The organization needs managers who know the organization of work, the principles of leadership, and international management well and progressing in a consistent manner with the socially accepted system of values that determines what is most important in life (Blanchard \& O'Connor, 2008, p. 119).

Contemporary manager must be specialist in the field of managing people in the organization and making reasonable decisions.

What the company needs is the governing principle that allows full development of the individual human forces and responsibility, and at the same time will give common direction to the sense of perspective and efforts, that will provide collectivity of work, harmonizing individual targets with common good. (Drucker, 2004, p. 154)

Managers should be aware that in today's economy the most important resource for companies are no longer raw materials, capital, and material assets, but the staff, their knowledge, skills, and motives in their quest for a better job, change, and progress.

They should also be aware that what is crucial to the success of the organization are their leadership initiatives arising from the knowledge, creativity, and commitment, and not from their position, their entrepreneurship, enthusiasm, or creative inspiration, rather than copying and reproduction of cliches.

Contemporary managers should create visionary ideas and concepts of operation in conjunction with the current competencies of the organization (distinctive competencies), taking into account long-term forecasts of the development and the opportunities created by acquisition, assimilation, and enrichment of knowledge, also continuous improvement and seeking opportunities for the company outside the country in which it is located.

\section{Summary}

Modern economy needs to improve management concept of entities in the complex world of international and global management. It also indicates the areas and issues that managers are facing today. It shows the opportunities arising from innovation and internationalization of enterprises. Contemporary problems, therefore, need new solutions and new approach, not only mercantile and marketing, but also a holistic, humanistic, and synthesizing economic value. The complexity of the requirements of the modern economy is a reason of managers and employees development, increase of resistance to stress, and ability to listen in connection with the mature human resources management, searching opportunities related to internationalization of the enterprise.

\section{References}

Bazzichi, O. (2003). Corporate social responsibility. Society, 3(4), 493-501.

Blanchard, K., \& O'Connor, M. (2008). Management by values. Warsaw.

Bloom, H., Calori, R., \& Woot, P. D. (1995). European managament. Poltext, Warsaw.

Crozier, M. (2003). Company of others. PWE, Warsaw.

Drucker, P. (2004). The practice of management. AE, Cracow, 154. 
Falck, F. (2003). Corporate culture and social responsibility. Society, 3(4), 417-427.

Hutt, M. D., \& Speh, T. W. (1997). Marketing management. PWN, Warsaw.

Grudzewski, W. M., \& Hejduk, I. K. (1997). The concept of creating an intelligent organization in companies. Organization and

Leadership, 4, 3-22.

Kay, J. (1996). Basics of business success. PWE, Warsaw.

McKenna, R. (1991). Marketing is everything. Harvard Business Review, 1(2), 63.

Penc, J. (2005). Reengeneering of the functioning company. Manager, 10, 37.

Penc, J. (2010). New management in the new economy. Warsaw.

Toffler, A., \& Toffler, H. (1996). Construction of the new organization. Politics of the Third Wave. Poznan: Profit and Ska.

Wawrzyniak, B. (1996). Understand the modern enterprise. School of Business and Management. Warsaw.

Wawrzyniak, B. (2007). Innovation and entrepreneurship in the reconstruction of Polish companies. KNOIZ PAN, Warsaw.

Zbiegień-Maciag, L. (1996). Ethics of management. CIM, Warsaw. 